\title{
Study of internal charging of four commonly used polymers through experimental and numerical analysis
}

Cite as: J. Appl. Phys. 125, 045108 (2019); https://doi.org/10.1063/1.5055221

Submitted: 06 September 2018 . Accepted: 15 December 2018 . Published Online: 30 January 2019

Rémi Pacaud (D), Thierry Paulmier, Pierre Sarrailh (D), Keith Ryden, Alex Hands, and Denis Payan
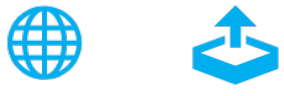

\section{ARTICLES YOU MAY BE INTERESTED IN}

CVD growth and properties of on-axis vanadium doped semi-insulating 4H-SiC epilayers Journal of Applied Physics 125, 045702 (2019); https://doi.org/10.1063/1.5057389

Reducing interfacial thermal resistance between metal and dielectric materials by a metal interlayer

Journal of Applied Physics 125, 045302 (2019); https://doi.org/10.1063/1.5079428

Design of semiconductor surface pits for fabrication of regular arrays of quantum dots and nanorings

Journal of Applied Physics 125, 045303 (2019); https://doi.org/10.1063/1.5064807

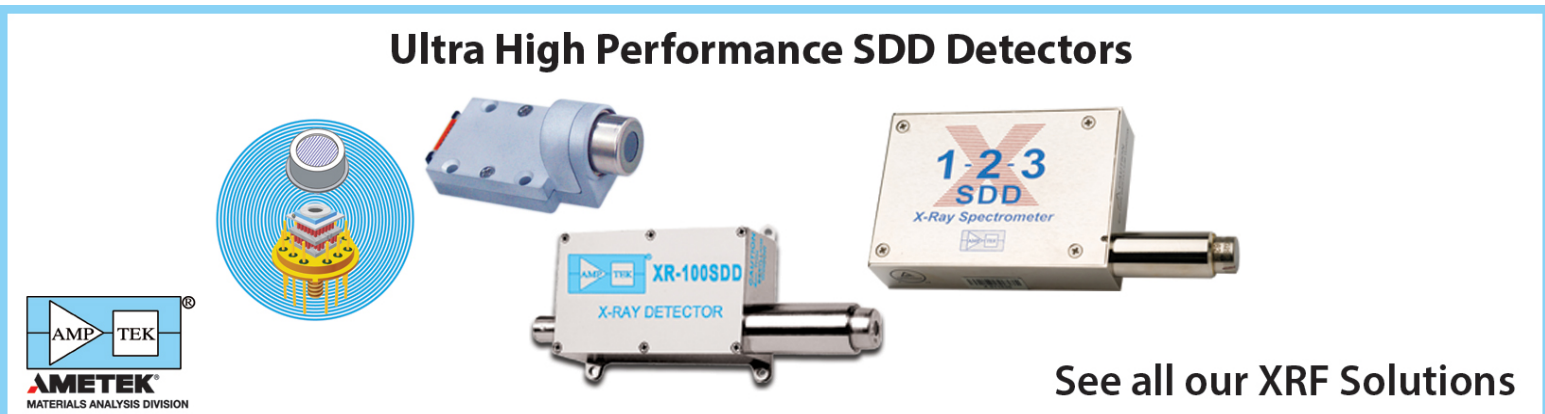




\title{
Study of internal charging of four commonly used polymers through experimental and numerical analysis
}

\author{
Cite as: J. Appl. Phys. 125, 045108 (2019); doi: 10.1063/1.5055221 \\ Submitted: 6 September 2018 . Accepted: 15 December 2018 . \\ Published Online: 30 January 2019
}

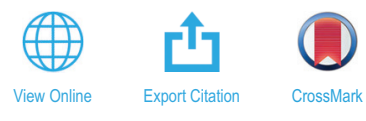

Rémi Pacaud, ${ }^{1, a)}$ (D) Thierry Paulmier, ${ }^{1, b)}$ Pierre Sarrailh, ${ }^{1, c)}$ (D) Keith Ryden, ${ }^{2, d)}$ Alex Hands, ${ }^{2, e)}$ and Denis Payan ${ }^{3, f)}$

\author{
AFFILIATIONS \\ ${ }^{7}$ ONERA, 2 Avenue Edouard Belin, 31000 Toulouse, France \\ ${ }^{2}$ Surrey Space Centre, University of Surrey, Guildford GU2 7XH, United Kingdom \\ ${ }^{3}$ CNES, 18 Avenue Edouard Belin, Toulouse, France \\ a)Remi.Pacaud@outlook.fr \\ b)Thierry.Paulmier@Onera.fr \\ c)Pierre.Sarrailh@Onera.fr \\ d) K.ryden@surrey.ac.uk \\ e)a.hands@surrey.ac.uk \\ f)Denis.Payan@Cnes.fr
}

\begin{abstract}
This paper focuses on the study of internal charging of four space used polymers: polyetheretherketone, fluorinated ethylene propylene, polyimide films, and epoxy based material (Epoxy FR4). Experiments were carried out for each material using the GEODUR facility (Toulouse, ONERA) that mimics the geostationary space environment behind shielding. Two different irradiation currents have been applied: $1 \mathrm{pA} / \mathrm{cm}^{2}$ and $10 \mathrm{pA} / \mathrm{cm}^{2} .1 \mathrm{pA} / \mathrm{cm}^{2}$ is used to analyze the charging behavior and the intrinsic electrical properties of each polymer. $10 \mathrm{pA} / \mathrm{cm}^{2}$ is used to study the influence of high electric field levels on their charging behavior. In this paper, two different numerical tools used for the study of internal charging are presented: Monte-Carlo Internal Charging Tool (MCICT) and Transport of Holes and Electrons Model under Irradiation in Space (THEMIS). MCICT has been used in the space community for several years. THEMIS has been recently developed at ONERA and is compared to MCICT. Both numerical tools showed consistent results for the $1 \mathrm{pA} / \mathrm{cm}^{2}$ integrated current but with deviations for the $10 \mathrm{pA} / \mathrm{cm}^{2}$ integrated current, supposedly due to nonlinear electric field effects on charge transport. THEMIS has a more refined physical model for the conductivity than MCICT. It studies more accurately the electron-polymer interactions and the charge transport kinetics of polymers under space radiations. Subsequently, the analysis of the underlying physical phenomena responsible for the polymers' charging behaviors will be carried out with THEMIS. In addition, studying these phenomena will permit to assess the risks of electrical discharges that may occur on a spacecraft in orbit (e.g., Geostationary (GEO) spacecraft) or during an elliptic trajectory (e.g., sub-GEO) in an Electric Orbit Raising case [E. Y. Choueiri, A. J. Kelly, and R. G. Jahn, J. Spacecr. Rockets 30(6), 749-754 (1993)].
\end{abstract}

Published under license by AIP Publishing. https://doi.org/10.1063/1.5055221

\section{INTRODUCTION}

In space, polymers are commonly used in satellites for their good physical, optical, and mechanical properties. They have to cope with high fluxes and high energetic charged particles such as electrons or protons. The electrostatic potential levels of these materials change differently over time from one material to another ${ }^{2}$ since polymers have different electrical properties. An example of such behavior has already been described in a previous paper, ${ }^{3}$ in which the surface potential kinetics of Teflon FEP ${ }^{\circledR}$ and Kapton $\mathrm{HN}^{\circledR}$ were compared. The experiment showed important differences in their surface potential profiles as well as high surface potential values. 
Such levels can lead to significantly high electric field values that can trigger electrostatic discharges (ESDs) and damage the satellite. In order to predict such events, the charging behavior of space used polymers is thoroughly studied. Two different cases of charging are identified. The first one is surface charging and the second one is internal charging. ${ }^{4-6}$ Figure 1 is a schematic of both cases.

In the case of surface charging, polymers are located upon the outer layers of the satellite and are the first materials to cope with space radiations. These are usually thermal blankets and solar arrays. Electrical discharges only occur between two close materials through vacuum and do not affect sensitive electronics.

In the case of internal charging, polymers are usually thick materials located in the inner parts of the satellite. They are used in circuit boards, insulator cables, or connectors. Internal charging is more dangerous than surface charging since electrical discharges may occur in the material bulk itself and affect sensitive electronics of the satellite. Internal charging processes are not straightforward due to complex electric field configurations. In addition, ionising dose and charge depositions are not as simple as in surface charging. The same high energetic particles are going through the external layers of the satellite and reach the inner layers and accumulate inside the material bulk (Fig. 1). For internal charging, implantation and ionization are always steered by the same incident electrons.

This paper is dedicated to the study of internal charging. The electrical properties of four different space used polymers are studied through analyses of their charging behavior. These are polyetheretherketone (PEEK, provided by VICTREX), fluorinated ethylene propylene (FEP Neoflon ${ }^{\circledR}$, provided by Daikin), polyimide films (Cirlex ${ }^{\circledR}$, provided by DuPont), and epoxy based material (Epoxy FR4). These polymers are irradiated using the GEODUR facility $^{7}$ (described in Sec. II) at ONERA. Two different integrated currents have been applied on these materials: $1 \mathrm{pA} / \mathrm{cm}^{2}$ and $10 \mathrm{pA} / \mathrm{cm}^{2}$. It allows studying the influence of an acceleration factor on the charging behavior. The experimental facility and protocol are detailed in Sec. II. The experimental

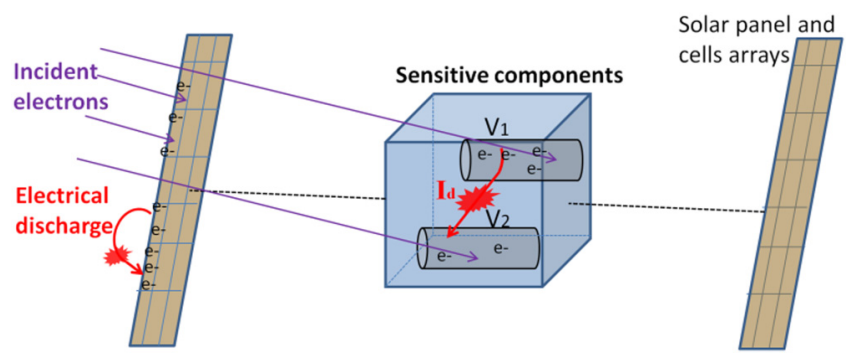

FIG. 1. Schematic presenting surface and internal charging on a spacecraft. The big blue box is the satellite core. Gray cylinders are sensitive components such as insulator cables or circuit boards. There is an electron accumulation on the solar panels and in the bulk of the sensitive components. The voltage difference between $V_{1}$ and $V_{2}$ induces an electrical discharge with a discharge current $I_{d}$ that damages the materials. results are compared with the numerical results (described in Sec. IV), obtained with two different numerical tools: Transport of Holes and Electrons Model under Irradiation in Space (THEMIS) $^{3}$ and Monte-Carlo Internal Charging Tool (MCICT) ${ }^{8}$ (described in Sec. III). These tools are used for the analysis of internal charging on spacecraft.

\section{EXPERIMENTAL SET-UP AND PROTOCOL}

The study of internal charging was made possible through the GEODUR facility ${ }^{7}$ installed at ONERA. The electron energy range extends from $400 \mathrm{keV}$ to $2 \mathrm{MeV}$, and the facility is equipped with a $2.5 \mathrm{MeV}$ Van de Graff electron accelerator as well as a double scattering system for the production of a distributed electron spectrum in the energy range of $100 \mathrm{keV}$ to $1 \mathrm{MeV}$. Figure 2 shows the $1 \mathrm{pA} / \mathrm{cm}^{2}$ integrated electron current spectrum as a function of their incident energy. Surface potential and current measurements are monitored using a Kelvin probe and a picoammeter. The temperature of the sample holder can be controlled in the range $\left[-180^{\circ} \mathrm{C}\right.$; $\left.+250{ }^{\circ} \mathrm{C}\right]$. In the frame of this project, the samples are irradiated at room temperature (approximately $20^{\circ} \mathrm{C}$ ). The facility is also equipped with a pumping system allowing an operation pressure of $10^{-6} \mathrm{~h} \mathrm{~Pa}$.

The experimental protocol is as follows: two sets of pristine samples have been tested. Each sample of each set was irradiated for $7 \mathrm{~h}$. After $7 \mathrm{~h}$ of irradiation, the electron beam was switched off and the samples were left being nonirradiated for another $17 \mathrm{~h}$. This is called the relaxation phase. The first set of samples was irradiated using an integrated current of $1 \mathrm{pA} / \mathrm{cm}^{2}$. The second set of samples was irradiated using an integrated current of $10 \mathrm{pA} / \mathrm{cm}^{2}$. Their surface potential was monitored during irradiation and relaxation. The sample thickness, composition, and supplier are referred in Table I. The results are detailed in Sec. IV.

Figure 3 represents a standard irradiation configuration of an irradiated sample for which we can monitor the surface potential $\mathrm{V}$ and the output current $\mathrm{I}_{\text {out }}$.

\section{GEODUR spectrum - Integrated current density : $1 \mathrm{pA} / \mathrm{cm}^{2}$}

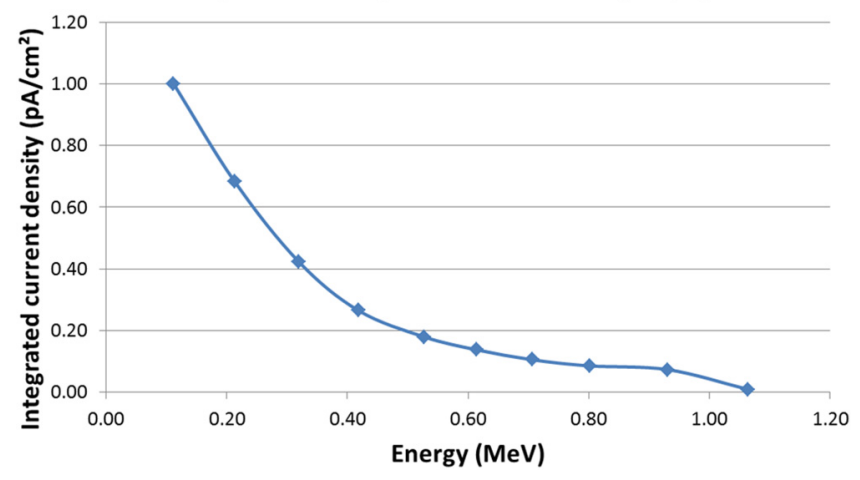

FIG. 2. GEODUR spectrum: electrons' integrated current density as a function of incident energy. The total integrated current density is $1 \mathrm{pA} / \mathrm{cm}^{2}$. 
TABLE I. Samples tested for the study of internal charging.

\begin{tabular}{|c|c|c|c|}
\hline Material & $\begin{array}{c}\text { Thickness } \\
(\mathrm{mm})\end{array}$ & Grade & Supplier \\
\hline Fluorinated ethylene propylene (FEP) & 0.5 & FEP Neoflon ${ }^{\circledR}$ & Daikin \\
\hline Polyetheretherketone (PEEK) & 0.5 & APTIV $1000^{\circledR}$ & VICTREX \\
\hline Epoxy based material & 1.5 & Epoxy FR4 & \\
\hline Polyimide & 1 & Cirlex $^{\circledR}$ & DuPont \\
\hline
\end{tabular}

\section{NUMERICAL TOOLS USED FOR THE STUDY OF INTERNAL CHARGING}

\section{A. The THEMIS numerical tool}

The Transport of Holes and Electrons Model under the Irradiation in Space (THEMIS) numerical tool has already been described in a previous paper. ${ }^{3}$ An overview of its main characteristics is presented hereunder, and a more detailed description is presented in the Appendix.

This tool, developed by ONERA since 2015, is used for the study of surface and internal charging. It simulates charge transport in one dimension (1D), in dielectric materials when they are irradiated with electrons under representative space conditions. Potential levels are computed with charge densities, using the Poisson equation. Conductivity levels are computed with the charge densities and the mobility of charges, such as

$$
\sigma=e n \mu_{n}+e p \mu_{p}
$$

where $n$ and $p$ are the electrons' and holes' densities, $\mu_{n}$ and $\mu_{p}$ are the electrons' and holes' mobility, and $e$ is the charge of an electron.

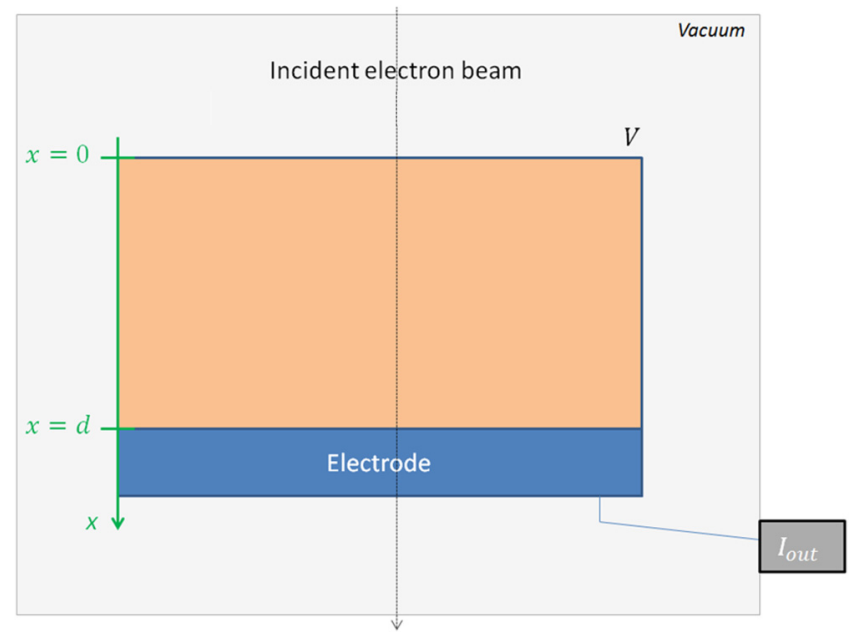

FIG. 3. One dimensional (1D) representation of a sample connected to a back face electrode and exposed to vacuum on its irradiated front face. $x=0$ represents the irradiated polymer surface and $x=d$ is the junction between the sample and the metal. $V$ is the surface potential monitored at $x=0$, and $I_{\text {out }}$ is the current monitored at $x=d$.
Unlike any other charging tools, THEMIS distinguishes the behavior of electrons and holes. It takes into account the fact that these two species have different trapping and de-trapping kinetics. It also considers the interactions between electrons and holes through recombination processes. It computes the electron implantation, ${ }^{9}$ the dose deposition, and the charge generation rate with empirical analytical equations (electron implantation and dose models were compared and validated with respect to Monte-Carlo simulations using the Casino tool ${ }^{10}$ ).

\section{B. The MCICT numerical tool}

The Monte-Carlo Internal Charging Tool (MCICT) is a one dimensional (1D) numerical tool, used for the description of internal charging in spacecraft. It was developed within the ESA JUICE Charging Analysis Tool project. ${ }^{8}$ In order to assess the charge and dose deposition profiles, it uses Monte-Carlo simulations. The surface potential is computed with Ohm's law. The conductivity is computed using Eqs. (2)-(6). In this model, the material is considered to be an RC circuit: a resistance in parallel to a capacitor

$$
\frac{d \mathrm{~V}}{d \mathrm{t}}=\frac{d}{\mathrm{~S} \varepsilon_{r} \varepsilon_{0}} \mathrm{I}_{\mathrm{c}}-\frac{\sigma}{\varepsilon_{r} \varepsilon_{0}} \mathrm{~V}(\mathrm{t})
$$

where $I_{c}$ is the deposited current, $d$ is the polymer thickness, $\mathrm{S}$ is the irradiated area, $\sigma$ is the total conductivity, $\varepsilon_{r} \varepsilon_{0}$ is the electric permittivity, and $t$ is the irradiation time. The total conductivity is the sum of two components. The first one is the radiation induced conductivity $\sigma_{\mathrm{RIC}}{ }^{11}$ and the second one is temperature and electric field dependent $\sigma(\mathrm{T}, \mathrm{E})^{12}$

$$
\sigma=\sigma_{\mathrm{RIC}}+\sigma(\mathrm{T}, \mathrm{E}) .
$$

The radiation induced conductivity can be referred as the Radiation Induced Conductivity (RIC) and is calculated with the following empirical equation:

$$
\sigma_{\mathrm{RIC}}=k_{p} \dot{\mathrm{D}}^{\Delta}
$$

where $k_{p}$ and $\Delta$ are experimentally derived constants and are material properties dependent, and $\dot{D}$ is the dose rate. The temperature and electric field dependent component of the conductivity are obtained with Eqs. (5) and (6)

$$
\begin{gathered}
\sigma_{\mathrm{DC}}(\mathrm{T})=\frac{\mathrm{C}}{k \mathrm{~T}} \exp \left(-\frac{\mathrm{E}_{\mathrm{A}}}{k \mathrm{~T}}\right), \\
\sigma(\mathrm{E}, \mathrm{T})=\sigma_{\mathrm{DC}}(\mathrm{T})\left(\frac{2+\cosh \left(\beta_{\mathrm{F}} \mathrm{E}^{\frac{1}{2}} / 2 k \mathrm{~T}\right)}{3}\right)\left(\frac{2 k \mathrm{~T}}{e \mathrm{E} \delta} \sinh \left(\frac{e \mathrm{E} \delta}{2 k \mathrm{~T}}\right)\right),
\end{gathered}
$$

where $\mathrm{C}$ is determined from the room-temperature dark conductivity $\sigma_{\mathrm{DC}}\left(\mathrm{T}_{0}\right), \mathrm{E}_{\mathrm{A}}$ is the material activation energy, $\delta$ is an experimentally jump distance, and $\beta_{F}=\sqrt{e^{3} / \pi \varepsilon_{r} \varepsilon_{0}}$. The jump distance has been set to $10 \AA$ for each polymer. An overview of the main parameters of MCICT is presented in Table II. 
TABLE II. MCICT input parameters.

\begin{tabular}{lcc}
\hline \hline Symbol & Designation & Unit (SI) \\
\hline$k_{p}$ & RIC coefficient & $\Omega^{-1} \mathrm{~m}^{-1}\left(\mathrm{~Gy}^{-1} \mathrm{~s}\right)^{\Delta}$ \\
$\sigma_{D C}$ & Dark conductivity & $\Omega^{-1} \mathrm{~m}^{-1}$ \\
$\Delta$ & Exponent for the dose rate in the RIC calculation & No unit \\
$E_{A}$ & Activation energy & $\mathrm{eV}$ \\
\hline
\end{tabular}

\section{RESULTS AND DISCUSSION}

In this section, the charging behavior of each polymer is first described with the experimental results. Then, it is explained with crossed comparisons between the experimental and numerical results (MCICT and THEMIS). A $1 \mathrm{pA} / \mathrm{cm}^{2}$ integrated current has been used. For THEMIS, an extended case with a $10 \mathrm{pA} / \mathrm{cm}^{2}$ integrated current has been used in order to study the influence of higher electric field levels on charge transport.

\section{A. Description of the experimental results}

The experimental surface potential levels, obtained with the GEODUR facility as a function of irradiation time, are presented in Fig. 4.

\section{Irradiation phase}

It is observed in Fig. 4 that FEP Neoflon ${ }^{\circledR}$ has the lowest charging kinetics, followed by PEEK, Epoxy FR4, and Cirlex ${ }^{\circledR}$. FEP Neoflon ${ }^{\circledR}$, PEEK, Epoxy FR4, and Cirlex ${ }^{\circledR}$ charge up, respectively, to $-250 \mathrm{~V},-1000 \mathrm{~V},-2000 \mathrm{~V}$, and $-4500 \mathrm{~V}$ within $7 \mathrm{~h}$ of irradiation. Only Cirlex ${ }^{\circledR}$ seems to have a linear increase. The other polymers present a slight curvature in their surface potential kinetics.

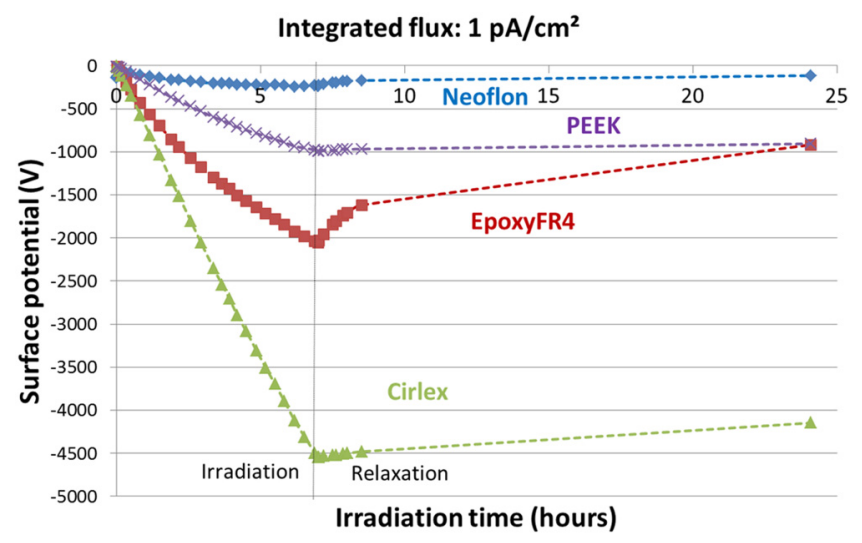

FIG. 4. Experimental (dashed lines) surface potential obtained for each polymer (FEP Neoflon ${ }^{\circledR}$, PEEK, Epoxy FR4, and Cirlex ${ }^{\circledR}$ ), with the GEODUR facility using an integrated current of $1 \mathrm{pA} / \mathrm{cm}^{2}$.

\section{Relaxation phase}

The surface potential of FEP Neoflon ${ }^{\circledR}$ shows a kinetic that corresponds to a fast decrease. It shows a potential drop during the first hour of relaxation, followed by a slow linear decrease during the rest of relaxation. Its surface potential decreases from $-250 \mathrm{~V}$ at the end of irradiation to $-125 \mathrm{~V}$ at the end of relaxation, which is $50 \%$ lower. The surface potential of Cirlex $^{\circledR}$ has a kinetic that corresponds to a lower decrease. We can see that this decrease is linear and its surface potential goes from $-4500 \mathrm{~V}$ to $-4100 \mathrm{~V}$, which is $9 \%$ lower. The decrease kinetics of PEEK are similar to Cirlex ${ }^{\circledR}$ as its surface potential goes from $-1000 \mathrm{~V}$ to $-900 \mathrm{~V}$, which is $10 \%$ lower. Epoxy FR4 has the fastest decrease kinetics. In the first $90 \mathrm{~min}$ of the relaxation phase, it decreases from $-2000 \mathrm{~V}$ to $-1600 \mathrm{~V}$ (20\% lower). During the rest of the relaxation, it shows the quickest linear decrease. From $-1600 \mathrm{~V}$, it reaches $-900 \mathrm{~V}$, which is $44 \%$ lower. These surface potential evolutions will be analyzed in Sec. IV C, using the physical model of THEMIS.

\section{B. Comparison of MCICT and THEMIS}

In this section, MCICT and THEMIS simulation results are compared to the experiments. We show that MCICT cannot explain the underlying physical phenomena responsible for the different charging behaviors of each polymer. These are studied with THEMIS, in Sec. IV C, as it is a more refined tool than MCICT.

Figure 5 displays the crossed comparisons between the experimental results and MCICT. Due to a lack of information on the electrical intrinsic properties of Epoxy FR4, it was not possible to run simulations with MCICT on that polymer. For PEEK, the numerical results yielded by MCICT are in very good agreement with the experiments during the irradiation. Both the kinetics and surface potential values are well

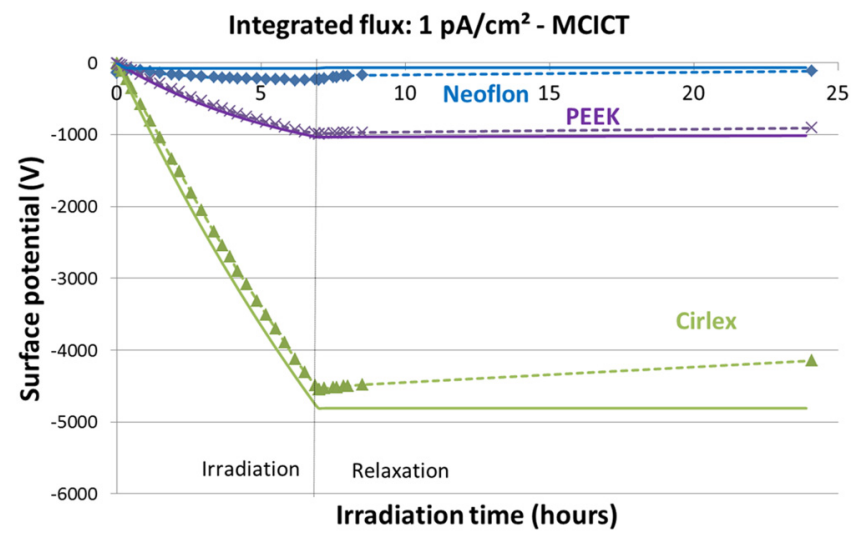

FIG. 5. Experimental (dashed lines) and numerical (continuous lines) surface potential obtained for each polymer (FEP Neoflon ${ }^{\circledR}$, PEEK, Epoxy FR4, and Cirlex ${ }^{\circledR}$ ), with the GEODUR facility, using an integrated current of $1 \mathrm{pA} / \mathrm{cm}^{2}$, and with MCICT. 
represented. The relative error is low during both phases. It reaches its highest value at the end of relaxation: only $11 \%$. However, MCICT shows a steady state during relaxation, related to a low dark conductivity, which is not seen in the experiments. If the relaxation kept going, it would mean that the relative error would increase linearly with time. For Cirlex $^{\circledR}$, only the irradiation phase is in very good agreement. During the relaxation phase, the experimental results show a slow decrease in the surface potential kinetics, whereas MCICT shows a steady state instead. After $17 \mathrm{~h}$ of relaxation, it gives a discrepancy of $800 \mathrm{~V}$. MCICT fails to represent the potential decrease, and the error would increase if relaxation kept going. For FEP Neoflon ${ }^{\circledR}$, the numerical surface potential values are not representative of the experiments as the relative error is superior to $100 \%$. In addition, MCICT shows a plateau $(-65 \mathrm{~V})$ during both irradiation and relaxation phases, whereas the experiments show a fast decrease kinetics.

Figure 6 displays the crossed comparisons between the experimental results and THEMIS. For Epoxy FR4, the relative error between the numerical and experimental results is significant (often superior to $20 \%$ or $30 \%$ ), during both phases. The kinetics is not well represented. THEMIS shows a strong bending during irradiation, which is not seen in the experiments. During relaxation, the slopes are different, which means that the discrepancy increases with time. The relative error reaches $67 \%$ at the end of relaxation, which would increase if relaxation kept going. For PEEK, the simulation results do not yield as good results as MCICT. Although the overall kinetics show a quite good agreement (linear increase during irradiation and very slow decrease during relaxation), the relative error is still high. It increases and reaches $40 \%$ at the end of irradiation and $50 \%$ at the end of relaxation. For Cirlex $^{\circledR}$, the agreement is slightly worse than MCICT during irradiation (relative error of $14 \%$ for THEMIS and $6 \%$ for MCICT) but much better during relaxation. Although THEMIS

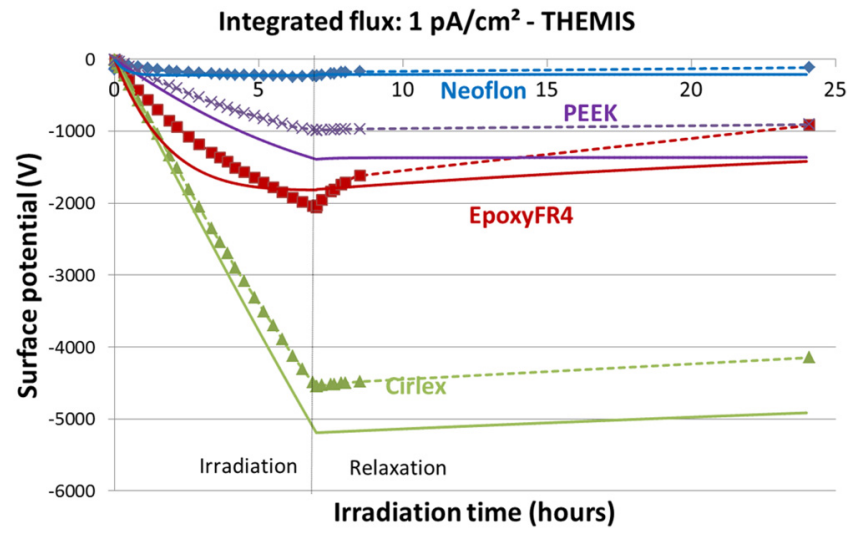

FIG. 6. Experimental (dashed lines) and numerical (continuous lines) surface potential obtained for each polymer (FEP Neoflon ${ }^{\circledR}$, PEEK, Epoxy FR4, and Cirlex $^{\circledR}$ ), with the GEODUR facility, using an integrated current of $1 \mathrm{pA} / \mathrm{cm}^{2}$, and with THEMIS. shows slightly higher relative error, it is very good at representing the decrease kinetics. For THEMIS, if the relaxation kept going, the relative error would not increase, unlike MCICT. The slopes of numerical and experimental results are almost identical. For FEP Neoflon ${ }^{\circledR}$, the agreement is better with THEMIS than MCICT. Although THEMIS also displays a steady state during the relaxation phase, the relative error with the experiments is much lower.

There are, as stated in the previous paragraph, discrepancies between the experiments and the numerical results of MCICT and THEMIS. However, the conductivity model of MCICT cannot explain the underlying physical phenomena that steer charge transport. This is a quite simple physical model based work by Fowler, ${ }^{11}$ who made the hypothesis that an induced equilibrium current has to be reached. To be verified, this hypothesis requires that the generation rate of electron-hole pairs must be in equilibrium with the recombination rate between electrons and holes. This hypothesis is not verified as the current varies over time, which is confirmed with the temporal evolution of the surface potential (Fig. 4). In addition, the $\sigma_{\text {RIC }}$ is not electric field dependent, as it should be. It has been shown in a previous paper ${ }^{13}$ that the electron-polymer interaction is electric field dependent. The physical parameters of MCICT, such as $k_{p}$ or $\Delta$, are not related to physical processes in such a case. The agreement of MCICT with the experimental results is only due to the fact that the conductivity parameters are fitted to work in this range of irradiation conditions. Therefore, the physical model of MCICT is not suited for explaining the underlying physical phenomena that steer charge transport. For these reasons, in order to understand the electron-polymer interactions and the charge transport kinetics, the physical model of THEMIS is used in Sec. IV C to describe the charging behavior of the aforementioned polymers.

\section{Analysis of the experimental results based on the physical model of THEMIS}

THEMIS distinguishes the behavior of electrons and holes and computes their densities using Nonlinear Partial Differential Equations (NPDE). Extracting the parameter of these NPDE from dedicated experiments, it allowed getting a good approximation for the polymers intrinsic physical parameters: gap energy, trapping time, de-trapping time, mobility of charges, and Schubweg constant (Refs. 14 and 15-electrons' and holes' lifetime-mobility product $-\tau_{n} \mu_{n}$, $\left.\tau_{p} \mu_{p}\right)$. These parameters enable understanding the electronpolymer interactions and charge transport on a microscopic scale. Based on the NPDE and the physical parameters, the convection currents of charges and the bulk conductivity profiles $\left(\sigma=e n \mu_{n}+e p \mu_{p}\right)$ are computed as a function of irradiation time.

\section{Integrated current: $1 \mathrm{pA} / \mathrm{cm}^{2}$}

In this section, polymers are compared in pairs. FEP Neoflon ${ }^{\circledR}$ and PEEK are first compared to each other, followed by PEEK and Cirlex ${ }^{\circledR}$, Cirlex $^{\circledR}$ and Epoxy FR4, and 
Epoxy FR4 and PEEK. The parameters of these polymers are compared in Secs. IV C 1 a and IV C 1 b, in order to explain the differences between their surface potential kinetics. These parameters are summarized in Table III at the end of Sec. IV C 1 a and their bulk conductivity is compared during the irradiation and relaxation phases.

a. Irradiation phase FEP Neoflon ${ }^{\circledR}$ and PEEK: At the very beginning of irradiation, when the surface potential is low, the initial potential slope only differs with the material thickness and relative permittivity. It can be seen by simplifying Eq. (2) at $t=0$

$$
\frac{d \mathrm{~V}}{d t}=\frac{d}{S \varepsilon_{r} \varepsilon_{0}} I_{c}
$$

Since FEP Neoflon ${ }^{\circledR}$ has the same thickness as PEEK but a relative permittivity lower by a factor of 1.7, it has a lower charging kinetics for short irradiation times as it can be seen in Fig. 6. After several hours of irradiation, we notice that FEP Neoflon ${ }^{\circledR}$ had already reached a steady state $(-250 \mathrm{~V})$. PEEK reaches $-1000 \mathrm{~V}$ at the end of irradiation, but no steady state is observed. If the irradiation kept going, the surface potential of PEEK would still increase. Such differences in charging kinetics cannot be solely ascribed to the relative permittivity. This difference should be due to conductivity intrinsic parameters.

First, the Schubweg constants of electrons and holes have been analyzed in order to know whether they differ between FEP Neoflon ${ }^{\circledR}$ and PEEK. THEMIS results showed that they have close intrinsic physical parameters, which means that their Schubweg constants are similar. The difference in their charging kinetics is thus ascribed to the electron-polymer interaction.

Second, the effective gap energy of the material has been investigated. It has been found with THEMIS that this effective gap energy differs by a factor of 100 between PEEK and FEP Neoflon ${ }^{\circledR}$. It means that, for one incident electron, the creation yield of electron-hole pairs within the material is one hundred times lower for PEEK than for FEP Neoflon ${ }^{\circledR}$ : the number of generated holes from the irradiation is much lower for PEEK. Subsequently, the holes' conduction currents have a weaker contribution in the case of PEEK and do not counterbalance as well as FEP Neoflon ${ }^{\circledR}$ the surface potential increase due to the electron implantation.

TABLE III. Intrinsic polymer parameters. The parameters explain the differences in their surface potential kinetics.

\begin{tabular}{|c|c|c|c|c|c|}
\hline \multicolumn{2}{|c|}{ Material parameters } & \multirow{2}{*}{$\begin{array}{c}\begin{array}{c}\text { FEP } \\
\text { Neoflon }^{\circledR}\end{array} \\
1.5 \times 10^{-12} \\
5 \times 10^{-12}\end{array}$} & \multirow{2}{*}{$\begin{array}{c}\text { PEEK } \\
5 \times 10^{-12} \\
6 \times 10^{-11}\end{array}$} & \multirow{2}{*}{ 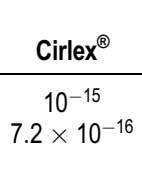 } & \multirow{2}{*}{$\begin{array}{c}\text { Epoxy FR4 } \\
2 \times 10^{-15} \\
7.5 \times 10^{-11}\end{array}$} \\
\hline $\begin{array}{l}\text { Schubweg } \\
\text { constant } \\
\left(\mathrm{m}^{2} \mathrm{~V}^{-1}\right)\end{array}$ & $\begin{array}{l}\text { Electrons } \\
\text { Holes }\end{array}$ & & & & \\
\hline Gap energy & & $2 \times 10^{-4}$ & & $1.4 \times 10^{-3}$ & $10^{-5}$ \\
\hline
\end{tabular}

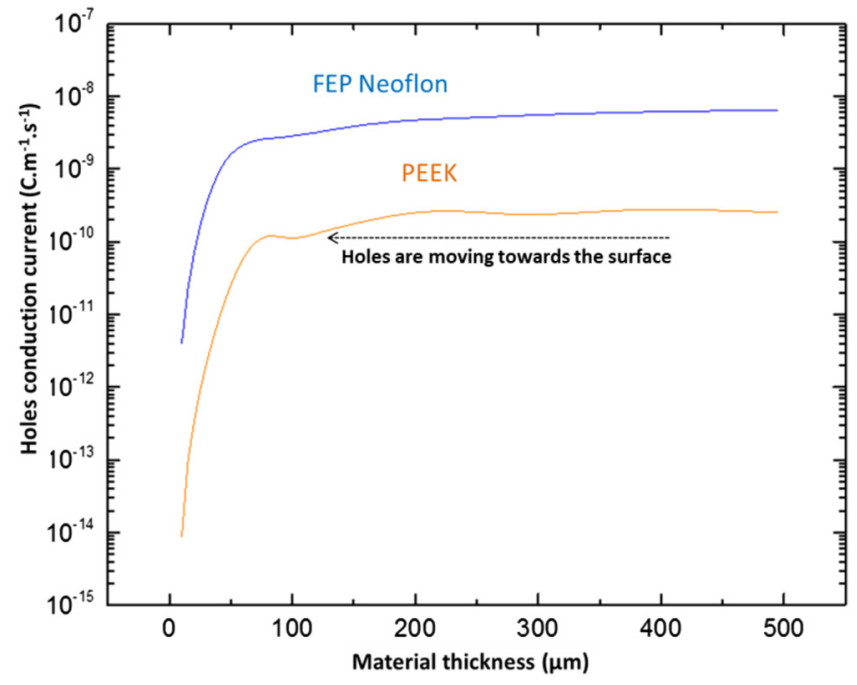

FIG. 7. Holes' conduction currents computed by THEMIS for FEP Neoflon ${ }^{\circledR}$ and PEEK as a function of the sample thickness.

The holes' conduction currents $\left(\mathrm{J}_{p}\right)$ have been plotted in Fig. 7 as a function of the material thickness. The gradients of these conduction currents $\left(\nabla J_{p}\right)$ have been computed and plotted in Fig. 8. They represent the holes' accumulation rate as a function of the position inside the material. Based on Figs. 7 and 8, it confirms that the number of holes that reaches the surface sample of FEP Neoflon ${ }^{\circledR}$ is greater than for PEEK.

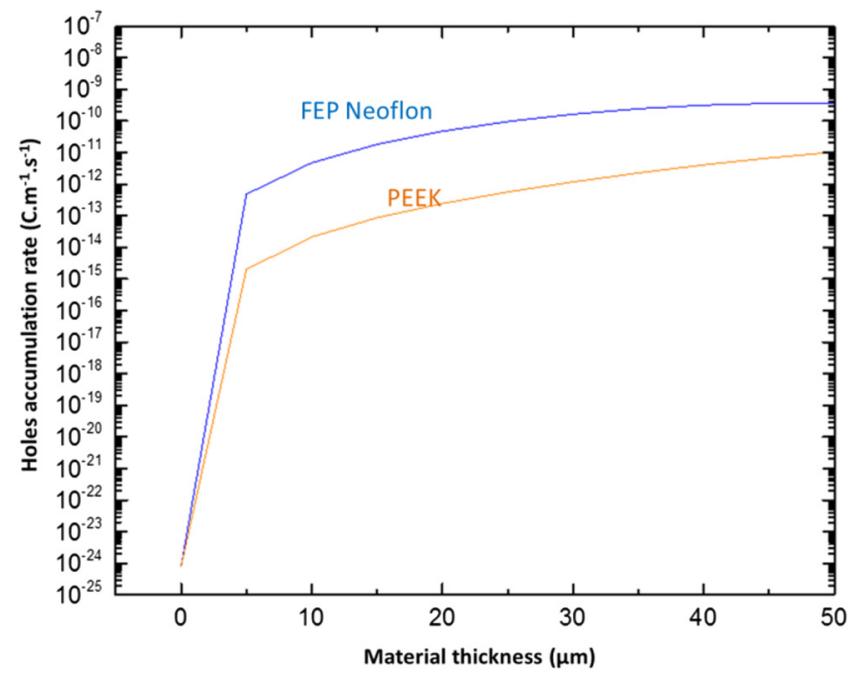

FIG. 8. Holes' accumulation rate computed by THEMIS for FEP Neoflon ${ }^{\circledR}$ and PEEK as a function of the sample thickness, within the first $50 \mu \mathrm{m}$ of the sample. 
Finally, the bulk conductivities of FEP Neoflon ${ }^{\circledR}$ and PEEK have been compared in Fig. 9 as a function of the irradiation time with THEMIS results. It shows that, during irradiation, $\sigma_{\text {PEEK }}<\sigma_{\text {FEP Neoflon }}$.

PEEK and Cirlex ${ }^{\circledR}$ : Cirlex $^{\circledR}$ and PEEK have a very close relative permittivity, but Cirlex $^{\circledR}$ is twice as thick as PEEK. It means that its capacitance is twice as low and explains that, for short irradiation times, a steeper charging kinetics is observed in Fig. 6. For longer irradiation times, a slight bending is observed for PEEK surface potential kinetics. It is not the case for Cirlex ${ }^{\circledR}$. In addition, after $7 \mathrm{~h}$ of irradiation, the surface potential of $\operatorname{Cirlex}^{\circledR}(-4500 \mathrm{~V})$ is 4.5 times higher than PEEK $(-1000 \mathrm{~V})$. In order to explain this behavior, the electrons' and holes' Schubweg constants were assessed and compared between Cirlex ${ }^{\circledR}$ and PEEK. It was found that the electrons' and holes' Schubweg constants of PEEK are four orders of magnitude higher than Cirlex ${ }^{\circledR}$. It means that electrons and holes in PEEK are highly mobile under the influence of an electric field. Subsequently, PEEK is more sensitive to the electric field effect than Cirlex $^{\circledR}$ and explains that $\sigma_{\text {Cirlex }}<\sigma_{\text {PEEK }}$ (Fig. 9).

Cirlex ${ }^{\circledR}$ and Epoxy FR4: Although Cirlex ${ }^{\circledR}$ is thinner than Epoxy FR4, it presents higher surface potential levels in Fig. 6. It is ascribed to a much higher holes' Schubweg constant from Epoxy FR4. It is five orders of magnitude higher than Cirlex $^{\circledR}$, which means that holes in Epoxy FR4 are highly mobile under the influence of an electric field. These holes, generated in the material bulk, move toward the surface sample and counterbalance the surface potential increase rate due to the electron implantation. Therefore, during irradiation, the bulk conductivity of Epoxy FR4 is higher than Cirlex ${ }^{\circledR}$ as seen in Fig. 9: $\sigma_{\text {Cirlex }}{ }<\sigma_{\text {Epoxy FR4 }}$.

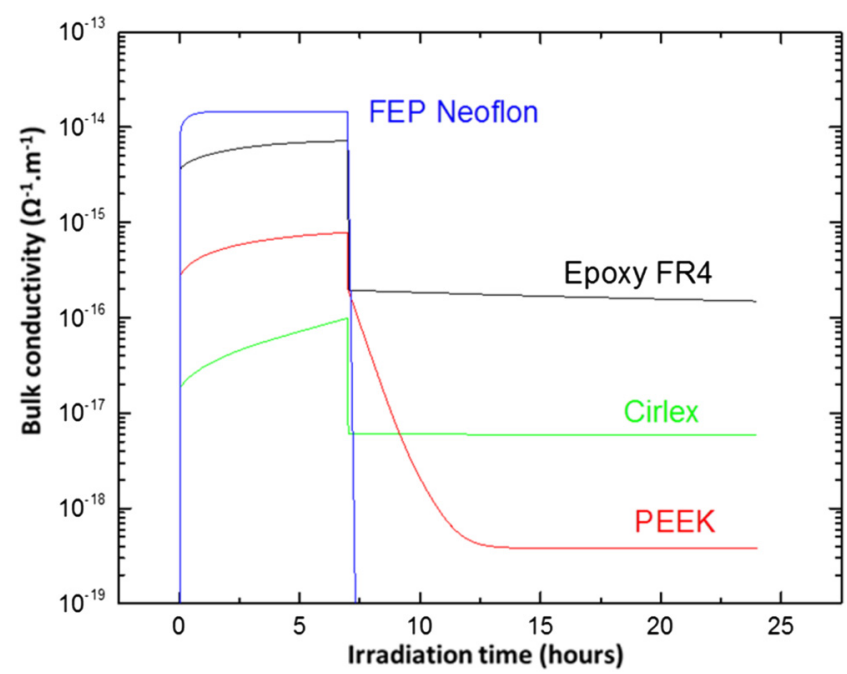

FIG. 9. Bulk conductivities computed with THEMIS as a function of irradiation time.
Epoxy FR4 and PEEK: PEEK is three times thinner than Epoxy FR4 but presents ten times lower conductivity levels (Fig. 9). Similarly to Cirlex ${ }^{\circledR}$, it is ascribed to the PEEK holes' Schubweg constant, which is three orders of magnitude lower than Epoxy FR4.

b. Relaxation phase FEP Neoflon ${ }^{\circledR}$ shows a significant surface potential decrease during relaxation. THEMIS ascribes this behavior to a high Schubweg constant for free holes. They are not instantaneously trapped but remain free for a short amount of time. During this period, due to a very high hole mobility, they have time to reach the sample surface and lower the surface potential levels. The conductivity of FEP Neoflon ${ }^{\circledR}$ has been plotted in Fig. 9 and shows a quick drop. It is due to an instantaneous trapping time for electrons, a very short trapping time for holes and a permanent trapping for both charges.

Cirlex ${ }^{\circledR}$ and PEEK both show slow surface potential decrease, but not for the same reasons. For Cirlex ${ }^{\circledR}$, THEMIS ascribes this behavior to the fact that, in comparison to FEP Neoflon ${ }^{\circledR}$, holes have both a low mobility and a quick trapping time. The hole Schubweg constant of Cirlex $^{\circledR}$ is four orders of magnitude below the hole Schubweg constant of FEP Neoflon ${ }^{\circledR}$. For PEEK, THEMIS ascribes this behavior to a very low hole mobility. Although holes have a longer trapping time than FEP Neoflon ${ }^{\circledR}$ (as it can be seen in Fig. 9 due to a long conductivity decay), they are very slow at reaching the sample surface. The conductivities of Cirlex ${ }^{\circledR}$ and PEEK have been plotted and compared in Fig. 9. Unlike PEEK, the conductivity of Cirlex ${ }^{\circledR}$ drops at the beginning of relaxation. The trapping time of holes and electrons are much lower than for PEEK. However, after $2 \mathrm{~h}$ of relaxation, the conductivity of $\mathrm{Cirlex}^{\circledR}$ is higher than PEEK. It is due to the fact that holes in Cirlex ${ }^{\circledR}$ have a low de-trapping characteristic time. They do not get permanently trapped, which explains that the bulk conductivity of Cirlex ${ }^{\circledR}$ remains high during relaxation.

Epoxy FR4 presents a very fast decrease kinetics in its potential levels. It is ascribed to a very high hole Schubweg constant, five orders of magnitude higher than Cirlex ${ }^{\circledR}$ and more than 1 time higher than FEP Neoflon ${ }^{\circledR}$. In addition, it has a low hole de-trapping characteristic time and a high electric field dependence on de-trapping, which explains that its conductivity levels remain high during relaxation.

\section{Integrated current: $10 \mathrm{pA} / \mathrm{cm}^{2}$}

Figure 10 displays the crossed comparisons between the experimental results and THEMIS for an integrated current of $10 \mathrm{pA} / \mathrm{cm}^{2}$. The relaxation phase is not displayed since an electrostatic discharge occurred in one of the polymers at the end of irradiation. It created a plasma cloud that expanded and neutralized all the samples.

In this experiment, an acceleration factor has been applied on the integrated current in order to study the effect of high electric field values on charge transport. Increasing the integrated current with a factor of 10 did not increase the surface potential values with the same factor. The surface potential levels for FEP Neoflon ${ }^{\circledR}$, PEEK, Epoxy FR4, and 


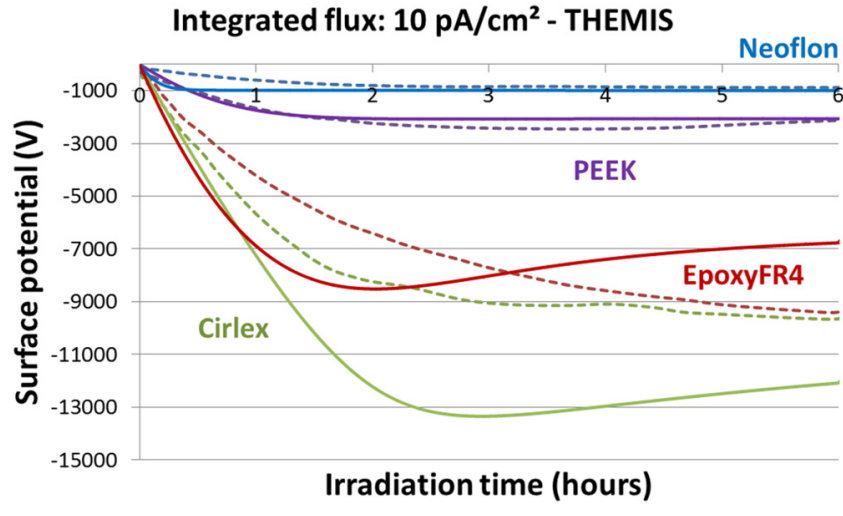

FIG. 10. Experimental (dashed lines) and numerical (continuous lines) surface potential obtained for each polymer (FEP Neoflon ${ }^{\circledR}$, PEEK, Epoxy FR4, and Cirlex ${ }^{\circledR}$ ), with the GEODUR facility, using an integrated current of $10 \mathrm{pA} / \mathrm{cm}^{2}$, and with THEMIS.

Cirlex ${ }^{\circledR}$ after $6 \mathrm{~h}$ of irradiation are, respectively, $-900 \mathrm{~V}$, $-2100 \mathrm{~V},-9400 \mathrm{~V}$, and $-9600 \mathrm{~V}$. In addition, the surface potential kinetics of Epoxy FR4 and Cirlex $^{\circledR}$ show a strong bending. Based on these results, it seems that Epoxy FR4 and Cirlex ${ }^{\circledR}$ have the strongest electric field dependence.

The numerical results do not agree as well with the experimental results as they did with the $1 \mathrm{pA} / \mathrm{cm}^{2}$ integrated current. It can be ascribed to nonlinear electric field effects on the electron-polymer interactions and other underlying physical phenomena that steer charge transport.

In a previous paper, ${ }^{13}$ a study performed on Kapton ${ }^{\circledR} \mathrm{HN}$ (a polyimide based material), using THEMIS, analyzed its surface potential levels. It showed that the electron-polymer interactions have a nonlinear dependence with the electric field and the temperature. This is called the geminate recombination, which has initially been described by Onsager. ${ }^{16}$ This dependence has only been described for Kapton ${ }^{\circledR} \mathrm{HN}$ and has not been studied for the polymers presented in this paper. Further studies should be envisaged in order to confirm this dependence.

In THEMIS, the electric field dependence has been taken into account into the electrons'/holes' mobility and de-trapping rate, with the Poole-Frenkel effect. ${ }^{17}$ This effect has been studied for Kapton ${ }^{\circledR} \mathrm{HN}$, but it is likely that the polymers studied in this paper behave differently with the electric field. If the other polymers do follow a Poole-Frenkel law, it should only mean that the current set of parameters has to be improved or that a real study on the effect of the electric field is needed, as done in Ref. 13.

\section{Assessment of electrical discharges}

This study's final objective is to assess the risks of electrical discharges between a polymer and a metal, in realistic irradiation cases. It showed that, from one polymer to another, the charging behavior varies with the integrated current. With a
$1 \mathrm{pA} / \mathrm{cm}^{2}$ integrated current, the potential levels of the four studied polymers are lower than with the $10 \mathrm{pA} / \mathrm{cm}^{2}$ integrated current. The latter induces a higher risk of electrical discharges. These risks also vary with the material geometry and its intrinsic electrical properties. However, polymers that get highly charged under electron irradiation are not necessarily the most dangerous materials. The relaxation ability of a material must be considered in an equivalent way as the charging ability. In order to understand this, we consider hereafter two irradiation cases. The first case takes place during a continuous irradiation period of time (for example, a GEO spacecraft in a GEO space storm) and the second during successive irradiation and relaxation phases [for example, with an elliptic trajectory, during an Electric Orbit Raising (EOR) case $\left.{ }^{1}\right]$.

(a) During a continuous irradiation case of a GEO spacecraft, charging events occur during a space storm. The whole process is a transient event (taking into account the time to populate the radiation belts and the relaxation phase) that usually lasts from one to three weeks. During that period of time, polymers cope with high fluxes of charged particles that get implanted in the bulk. ${ }^{18}$ An electrical breakdown occurs more easily for Epoxy FR4 than for PEEK, since Epoxy FR4 has a higher charging kinetics (Fig. 4).

(b) During an EOR case ${ }^{18}$ when a satellite is set into orbit and has an elliptic trajectory, it periodically enters and leaves the radiation belts and consecutively undergoes irradiation and relaxation phases. When the satellite leaves the radiation belts, the surface potential levels of Epoxy FR4 may have time to decrease by relaxation, whereas this is not the case for PEEK. The latter may have a worse relaxation kinetics in comparison to Epoxy FR4, which means that the risks of electrical discharges are probably greater in this irradiation case for PEEK.

\section{CONCLUSIONS AND PROSPECTS}

A study based on four space used polymers (FEP Neoflon ${ }^{\circledR}$, PEEK, EpoxyFR4, and Cirlex ${ }^{\circledR}$ ) has been carried out in this paper. The main objective was to understand their charging behavior by understanding the physical effects that steer the electron-polymer interactions and charge transport. This study allowed us to compare two numerical tools used for the study of internal charging.

\section{A. Analysis of the charging behavior and charge transport}

First, the polymers charging behavior has been studied under a $1 \mathrm{pA} / \mathrm{cm}^{2}$ integrated current with two different numerical tools: MCICT and THEMIS. THEMIS showed similar results to MCICT, but it is built on a more refined model. Subsequently, it allowed understanding charge transport at a microscopic scale. It not only distinguishes the behavior of electrons and holes, but it also showed that holes have a major role in charge transport, due to their Schubweg constant. 
Second, their charging behavior was studied using a $10 \mathrm{pA} / \mathrm{cm}^{2}$ integrated current. Higher fluxes lead to higher electric field levels, which showed nonlinear effects on charge transport. The numerical results did not agree as well as the $1 \mathrm{pA} / \mathrm{cm}^{2}$ integrated current. THEMIS ascribed these discrepancies to nonlinear electric field effects on the de-trapping characteristic time and mobility of charges (Poole-Frenkel effect). A previous study, ${ }^{13}$ performed on Kapton $\mathrm{HN}^{\circledR}$, showed the significance of these effects on charge transport, but it was carried out on another polymer, different from the ones studied in this paper. Further studies should be considered in order to know whether the Poole-Frenkel effect prevails in these materials.

The overall discrepancies between the experimental and numerical results may partly be explained to backscatter electrons on the chamber walls that are not taken into account in the simulations. A previous study led at ONERA showed that the number of backscattered electrons depends on the applied integrated current. This number can take values up to one third of the incident flux that should modify the charging behavior of the polymers.

\section{B. Comparison of MCICT and THEMIS}

The comparison of 2 different numerical tools was performed. MCICT and THEMIS both showed a good agreement with low integrated fluxes and slightly worse with high integrated fluxes. The input parameters used for the conductivity calculation in MCICT have no physical meaning and its physical model cannot explain the physical underlying processes that steer charge transport, which, on the contrary, THEMIS is able to do. The latter distinguishes the behavior of electrons and holes and enables a more thorough description for the physics of charge transport. It computes the surface potential, the bulk conductivity, and the convection currents of charges using partial differential equations. These NPDE take into account the materials' radiative history. The physical model of THEMIS allows studying more complicated irradiation cases, such as Electric Orbit Raising, with time-dependent electrons' spectra and various configurations: different material geometries, electric field levels, temperatures, etc.

\section{ACKNOWLEDGMENTS}

The authors thank the region Occitanie and ONERA for their Ph.D. funding, for Rémi Pacaud. This work has been performed in collaboration with the Surrey Space Centre, University of Surrey. In addition, the authors thank the CNES for its R\&T program, which enabled carrying out this study.

\section{APPENDIX: THE THEMIS NUMERICAL TOOL}

In order to assess the potential $\mathrm{V}$, the Poisson equation is associated with a Robin and a Dirichlet boundary condition. These boundary conditions mimic, respectively, the electric field behavior in vacuum and the metal interface. They are described by the first, second, and third equations of system (A1)

$$
\left\{\begin{array}{l}
-\Delta \mathrm{V}(x)=\frac{\rho(x)}{\varepsilon} \\
\left.\nabla \mathrm{V}(x)\right|_{x=0}-\frac{\varepsilon_{0}}{\varepsilon} \frac{\mathrm{V}(x)}{\mathrm{L}}=0 \\
\mathrm{~V}(d)=0
\end{array}\right.
$$

In system (A1), $\mathrm{V}$ is the potential, $\varepsilon$ is the dielectric permittivity, $\varepsilon_{0}$ is the vacuum permittivity, $d$ represents the material length, $L$ is the distance between the front surface material and the first surface electrically grounded, and $\rho$ is the total charge density described by Eq. (A2)

$$
\frac{\rho(x)}{e}=-n(x)+p(x)-n_{t}(x)+p_{t}(x)
$$

where $e$ is the elementary charge (C), $n$ is the density of free electrons $\left(\mathrm{m}^{-3}\right), p$ is the density of free holes $\left(\mathrm{m}^{-3}\right), n_{t}$ is the density of trapped electrons $\left(\mathrm{m}^{-3}\right)$, and $p_{t}$ is the trapped holes' density $\left(\mathrm{m}^{-3}\right)$.

As mentioned before, the THEMIS tool distinguishes the behavior of electrons from the behavior of holes. Equations of system (A3) represent, respectively, the free electrons, trapped electrons, free holes, and trapped holes' time derivative function

$$
\left\{\begin{array}{l}
\frac{\partial n(x, t)}{d t}=g(x, t)-\frac{\nabla \cdot j_{0}}{e}-\nabla \cdot J_{n}-R_{1}-R_{2}-\frac{n}{\tau_{n}}+\frac{n_{t}}{\tau_{n t}} \\
\frac{\partial n_{t}(x, t)}{d t}=-R_{3}+\frac{n}{\tau_{n}}-\frac{n_{t}}{\tau_{n t}} \\
\frac{\partial p(x, t)}{d t}=g(x, t)+\nabla \cdot J_{p}-R_{3}-R_{2}-\frac{p}{\tau_{p}}+\frac{p_{t}}{\tau_{p t}} \\
\frac{\partial p_{t}(x, t)}{d t}=-R_{1}+\frac{p}{\tau_{p}}-\frac{p_{t}}{\tau_{p t}} \\
\left.\mathrm{~J}_{n}(x, t)\right|_{x=0}=0 \\
\left.\left(\nabla \cdot J_{n}\right)\right|_{x=d}=0 \\
\left.J_{p}(x, t)\right|_{x=0}=0 \\
\left.\left(\nabla \cdot J_{p}\right)\right|_{x=d}=0 \mid
\end{array}\right.
$$

These functions are dependent of several terms: $g(x, t)$ is the generation rate of free electrons and holes $\left(\mathrm{m}^{-3} \mathrm{~s}^{-1}\right)$. It is electric field dependent as described in a previous paper. ${ }^{13}$ $\nabla \cdot j_{0}$ is the incident electrons' implantation current in the material $\left(\mathrm{C} \mathrm{m}^{-3} \mathrm{~s}^{-1}\right) ; \tau_{n}, \tau_{n_{\mathrm{t}}}, \tau_{p}$, and $\tau_{p_{\mathrm{t}}}$ are, respectively, the trapping characteristic time and the de-trapping characteristic time for electrons and holes $\left(\mathrm{s}^{-1}\right)$. The de-trapping characteristic time of holes is electric field dependent as described in Ref. 13.

In system (A3), we set two boundary conditions. For the first one, we chose the electrons' and holes' current to be zero at the boundary between the polymer and vacuum. For the second one, an unlimited current of free populations at the metal/dielectric interface has been chosen.

The electrons' and holes' current densities are computed with system (A4)

$$
\left\{\begin{array}{l}
\mathrm{J}_{n}=\mathrm{J}_{n}^{\text {Convection }}+\mathrm{J}_{n}^{\text {Diffusion }}=n \mu_{n} \mathrm{E}+\mathrm{D}_{n} \nabla n, \\
\mathrm{~J}_{p}=\mathrm{J}_{p}^{\text {Convection }}+\mathrm{J}_{p}^{\text {Diffusion }}=p \mu_{p} \mathrm{E}+\mathrm{D}_{p} \nabla p .
\end{array}\right.
$$


TABLE IV. THEMIS input parameters.

\begin{tabular}{|c|c|c|}
\hline Symbol & Designation & Unit (SI) \\
\hline$\tau_{n}$ & Trapping characteristic time of free electrons & $\mathrm{s}$ \\
\hline$\tau_{p}$ & Trapping characteristic time of free holes & s \\
\hline$\tau_{n_{t}}$ & De-trapping characteristic time of trapped electrons & $\mathrm{s}$ \\
\hline$\tau_{p_{t}}$ & De-trapping characteristic time of trapped holes & $\mathrm{S}$ \\
\hline$\mu_{n}$ & Mobility coefficient of free electrons & $\mathrm{m}^{2} \mathrm{~V}^{-1} \mathrm{~s}^{-1}$ \\
\hline$\mu_{p}$ & Mobility coefficient of free holes & $\mathrm{m}^{2} \mathrm{~V}^{-1} \mathrm{~s}^{-1}$ \\
\hline$D_{n}$ & Diffusion coefficient of free electrons & $\mathrm{m}^{2} \mathrm{~s}^{-1}$ \\
\hline$D_{p}$ & Diffusion coefficient of free holes & $\mathrm{m}^{2} \mathrm{~s}^{-1}$ \\
\hline$\alpha_{n p}$ & $\begin{array}{l}\text { Recombination coefficient between free electrons and free } \\
\text { holes }\end{array}$ & $\mathrm{m}^{3} \mathrm{~s}^{-1}$ \\
\hline$\alpha_{p n_{t}}$ & $\begin{array}{l}\text { Recombination coefficient between free holes and trapped } \\
\text { electrons }\end{array}$ & $\mathrm{m}^{3} \mathrm{~s}^{-1}$ \\
\hline$\alpha_{n p_{t}}$ & $\begin{array}{l}\text { Recombination coefficient between free electrons and } \\
\text { trapped holes }\end{array}$ & $\mathrm{m}^{3} \mathrm{~s}^{-1}$ \\
\hline$r_{0}$ & $\begin{array}{l}\text { Initial separation distance between an electron and its } \\
\text { parent atom (Ref. 19) }\end{array}$ & $\mathrm{m}$ \\
\hline$\varphi_{0}$ & $\begin{array}{l}\text { Efficiency of production of thermalized ion pairs per } \\
\text { absorbed electron (Ref. 19) }\end{array}$ & No unit \\
\hline $\boldsymbol{\beta}$ & $\begin{array}{l}\text { Coefficient related to the decrease of the Coulomb barrier } \\
\text { under the influence of an electric field (Ref. 17) }\end{array}$ & $m^{1 / 2} V^{-1 / 2}$ \\
\hline$E_{g}$ & $\begin{array}{l}\text { Gap energy between a deep trap and the conduction } \\
\text { band }\end{array}$ & $\mathrm{eV}$ \\
\hline
\end{tabular}

System (A4) describes the electrons' current density, $\mathrm{J}_{n}\left(\mathrm{~m}^{-2} \mathrm{~s}^{-1}\right)$, and the holes' current density $\mathrm{J}_{p}\left(\mathrm{~m}^{-2} \mathrm{~s}^{-1}\right) \cdot \mu_{n}$ and $\mu_{p}$ are the electrons and holes' mobility. $D_{n}$ and $D_{p}$ are their diffusion coefficients. The total current density is the sum of the convection and diffusion current density. In Ref. 13, it has been showed that conductivity in Kapton HN is steered by the electric field. We think it can be extended to other polymers. This dependence was added to the model and taken into account as described in a previous paper. ${ }^{13}$

System (A5) describes the recombination terms between electrons and holes. $R_{1}$ corresponds to the recombination of free electrons with trapped holes $\left(\mathrm{m}^{-3} \mathrm{~s}^{-1}\right) . \mathrm{R}_{2}$ corresponds to the recombination of free electrons with free holes $\left(\mathrm{m}^{-3} \mathrm{~s}^{-1}\right)$. $R_{3}$ corresponds to the recombination of free holes with trapped electrons $\left(\mathrm{m}^{-3} \mathrm{~s}^{-1}\right)$

$$
\left\{\begin{array}{l}
\mathrm{R}_{1}=\alpha_{1} n p_{\mathrm{t}}, \\
\mathrm{R}_{2}=\alpha_{2} n p, \\
\mathrm{R}_{3}=\alpha_{3} n_{\mathrm{t}} p .
\end{array}\right.
$$

Table IV summarizes the different input parameters required by the THEMIS numerical tool. There are 15 parameters but some of them are either neglected or assessed from others. Therefore, it is possible to reduce the number of parameters down to 10 . Their values change from one polymer to the other and are determined with crossed comparisons between experimental and numerical results.

\section{REFERENCES}

${ }^{1}$ E. Y. Choueiri, A. J. Kelly, and R. G. Jahn, "Mass savings domain of plasma propulsion for LEO to GEO transfer," J. Spacecr. Rockets 30(6), 749-754 (1993).

${ }^{\mathbf{2}}$ R. Hanna et al., "Radiation induced conductivity in Teflon FEP irradiated with multienergetic electron beam," IEEE Trans. Plasma Sci. 41(12), 3520-3525 (2013).

${ }^{3}$ R. Pacaud, T. Paulmier, and P. Sarrailh, "1-D physical model of charge distribution and transport in dielectric materials under space radiations," IEEE Trans. Plasma Sci. 45(8), 1947-1954 (2017).

${ }^{4}$ K. A. Ryden, A. D. P. Hands, C. I. Underwood, and D. J. Rodgers, "Internal charging measurements in medium earth orbit using the SURF sensor: 2005-2014," IEEE Trans. Plasma Sci. 43(9), 3014-3020 (2015).

${ }^{5} \mathrm{~A}$. Hands and K. Ryden, "Experimental measurement of low-intensity and long-duration internal charging behavior," IEEE Trans. Plasma Sci. 45(8), 1938-1946 (2017).

6J.-C. Matéo-Vélez, A. Sicard, D. Payan, N. Ganushkina, N. P. Meredith, and I. Sillanpäa, "Spacecraft surface charging induced by severe environments at geosynchronous orbit," Space Weather 16(1), 89-106 (2018).

${ }^{7}$ T. Paulmier, B. Dirassen, M. Belhaj, V. Inguimbert, D. Payan, and N. Balcon, "Experimental test facilities for representative characterization of space used materials," in 13th Spacecraft Charging Technology Conference, Pasadena, CA, 23-27 June 2014.

${ }^{8}$ F. Lei, D. Rodgers, and P. Truscott, "MCICT-Monte-Carlo Internal Charging Tool," in 14th Spacecraft Charging Technology Conference, Noordwijk, 4-8 April 2016.

${ }^{9}$ W. Lima and C. R. D. Poly, Generalized Empirical Equation for the Extrapolated Range of Electrons in Elemental and Compound Materials (International Atomic Energy Agency, Vienna, Austria), 359 p., ISSN 1011-4289; Worldcat, 1999, pp. 249-256; Symposium on techniques for high dose dosimetry in industry, agriculture and medicine, Vienna, Austria, 2-5 November 1998.

${ }^{10} \mathrm{H}$. Demers et al., "Three-dimensional electron microscopy simulation with the CASINO Monte Carlo software," Scanning 33(3), 135-146 (2011).

${ }^{11} \mathrm{~J}$. F. Fowler and Herbert Fröhlich, "X-ray induced conductivity in insulating materials," Proc. R. Soc. Math. Phys. Eng. Sci. 236(1207), 464-480 (1956).

${ }^{12} \mathrm{~V}$. Adamec and J. H. Calderwood, "Electrical conduction in dielectrics at high fields," J. Phys. Appl. Phys. 8(5), 551-560 (1975).

${ }^{13}$ R. Pacaud, T. Paulmier, and P. Sarrailh, "Electric field dependence on the conductivity of Kapton-HN: Integration into a 1D physical model used for the description of charge transport in dielectric materials under space environment," J. Appl. Phys. 122(24), 245106 (2017).

${ }^{14}$ G. M. Sessler and G. M. Yang, "Charge transport in Teflon and Kapton," in Proceedings of 1995 Conference on Electrical Insulation and Dielectric Phenomena, Virginia Beach, VA, 22-25 October 1995 (IEEE, 1995), pp. 630-633.

${ }^{{ }^{5}}$ H. Seggern, B. Gross, and D. A. Berkley, "Constant hole Schubweg in Teflon FEP (fluorinated ethylene propylene copolymer)," Appl. Phys. Solids Surf. 34(3), 163-166 (1984).

${ }^{16} \mathrm{~L}$. Onsager, "Initial recombination of ions," Phys. Rev. 54(8), 554-557 (1938).

${ }^{17}$ S. D. Ganichev, E. Ziemann, W. Prettl, I. N. Yassievich, A. A. Istratov, and E. R. Weber, "Distinction between the Poole-Frenkel and tunneling models of electric-field-stimulated carrier emission from deep levels in semiconductors," Phys. Rev. B 61(15), 10361-10365 (2000).

${ }^{18}$ R. B. Horne and D. Pitchford, "Space weather concerns for all-electric propulsion satellites," Space Weather 13(8), 430-433 (2015).

19J. Boch, F. Saigne, L. Dusseau, and R. D. Schrimpf, "Temperature effect on geminate recombination," Appl. Phys. Lett. 89(4), 042108 (2006). 